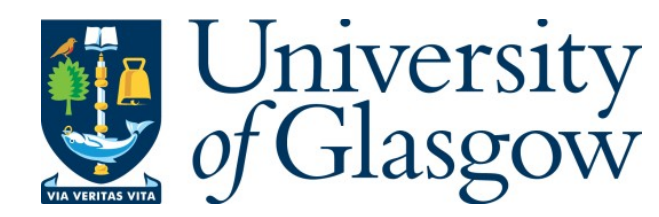

Li, S.-b., Wang, Z.-g., Barakos, G. N., Huang, W., and Steijl, R. (2016) Research on the drag reduction performance induced by the counterflowing jet for waverider with variable blunt radii. Acta Astronautica, 127, pp. 120-130.

There may be differences between this version and the published version. You are advised to consult the publisher's version if you wish to cite from it.

http://eprints.gla.ac.uk/120121/

Deposited on: 13 June 2016

Enlighten - Research publications by members of the University of Glasgow http://eprints.gla.ac.uk 


\title{
Research on the drag reduction performance induced by the counterflowing jet for waverider with variable blunt radii
}

\author{
Shi-bin $\mathrm{Li}^{1}$, Zhen-guo Wang ${ }^{1}$, George N. Barokos ${ }^{2}$, Wei Huang ${ }^{* 1}$, Rene Steijl ${ }^{2}$ \\ ${ }^{1}$ Science and Technology on Scramjet Laboratory, National University of Defense Technology, Changsha, Hunan 410073, People's
}

Republic of China

${ }^{2}$ CFD Laboratory, School of Engineering, University of Glasgow, UK.

\begin{abstract}
Waverider will endure the huge aero-heating in the hypersonic flow, thus, it need be blunt for the leading edge. However, the aerodynamic performance will decrease for the blunt waverider because of the drag hoik. How to improve the aerodynamic performance and reduce the drag and aero-heating is very important. The variable blunt radii method will improve the aerodynamic performance, however, the huge aero-heating and bow shock wave at the head is still serious. In the current study, opposing jet is used in the waverider with variable blunt radii to improve its performance. The three-dimensional coupled implicit Reynolds-averaged
\end{abstract} Navier-Stokes(RANS) equation and the two equation SST $k$ - $\omega$ turbulence model have been utilized to obtain the flow field properties. The numerical method has been validated against the available experimental data in the open literature. The obtained results show that the $L / D$ will drop $7 \sim 8 \%$ when $R$ changes from 2 to 8 . The lift coefficient will increase, and the drag coefficient almost keeps the same when the variable blunt radii method is adopted, and the $L / D$ will increase. The variable blunt radii method is very useful to improve the whole characteristics of blunt waverider and the $L / D$ can improve $3 \%$. The combination of the variable blunt radii method and opposing jet is a novel way to improve the whole performance of blunt waverider, and $L / D$ can improve $4 \sim 5 \%$. The aperture as a novel way of opposing jet is suitable for blunt waverider and also useful to improve the aerodynamic and aerothermodynamic characteristics of waverider in the hypersonic flow. There is

\footnotetext{
*Associate Professor, Corresponding author, E-mail address: gladrain2001@163.com, Phone: +86 73184576447
} 
the optimal $P_{0 \text { in }} / P_{0}$ that can make the detached shock wave reattach the lower surface again so that the blunt waverider can get the better aerodynamic performance.

Keywords: hypersonic, variable, blunt, waverider, lift-to-drag ratio, counterflowing jet

\section{Introduction}

Interest in the development of various types of hypersonic vehicles has been kept for several decades. One type of vehicles that are promising for hypersonic flight is the waverider, which first proposed by Nonweiler [1] in 1959. Waverider is a lifting body derived from a known analytical flow field such as flow around a cone and designed analytically with an infinitely sharp leading edge for shock-wave attachment. The attached shock wave can act as a barrier in order to prevent spillage of higher-pressure airflow from the lower side of the vehicle to the upper side, thus generate a high lift-to-drag $(L / D)$ at a high Mach number [2]. At the same time, the waverider can break the " $L / D$ barrier” which is proposed by Kuchemann [3] for hypersonic aircrafts. Therefore, the waverider is a good candidate for hypersonic flight [4]-[10]. Nowadays, there have been some remarkable vehicles which are designed based on waverider configuration, such as X-51A [11] and HTV-2.

However, it is extremely difficult to construct a perfectly sharp leading edge to achieve the attached shock-wave. Any manufacturing error will result in a significant deviation from the design contour. The sharp leading edge is not only difficult to maintain in the hypersonic flight condition, but also is difficult in manufacturing technology and impossible to achieve in practice. Thus, the leading edge should be blunt for heat transfer, manufacturing and handling concerns for practical hypersonic configurations [12]. Because a blunt leading edge promotes shock-wave standoff, shock detachment will occurs, making leading-edge blunting a major concern in the design and research on flowfield over hypersonic blunt waveriders. At the same time, the blunt leading edge will result in the drag increase, and there is a strong aero-heating along the leading edge at 
hypersonic flight speeds. For this, many researches had been done to improve the aerodynamic performance of blunt waverider. The experiment that Gillum and Lewis [13] had done for AEDC waverider showed that the $(L / D)_{\max }$ of waverider reduces $19.74 \%$ with the blunt leading edge. The numerical investigation of Cao and $\mathrm{Li}$ [14] also showed that bluntness has a great effect on its aerodynamic performance, especially the drag and $L / D$. And, the impact of bluntness on the aerodynamic and aero-heating performance of waverider was taken into account synthetically by Santos [15][16] and Chen [17][18]. Their results showed that aerodynamic performance and aero-heating are highly sensitive to the bluntness of waverider. Starkey [19] made a study on the performances of a $22 \mathrm{~m}$ osculating cone-based waverider with different blunt radius, and the results implied that there could be an intermediate design point with a good balance between the vehicle aerodynamic and aero-heating concerns. Vanmol and Anderson [20] had defined the blunt radius varied in the span direction and studied the heat transfer characteristics for waverider. They suggested a formula to get the minimum leading edge radius based on the low density effects. Numerical and experimental studies were developed on waverider with blunt leading edge by Liu [21][22] at Ma=10. The aerodynamic performance and aero-heating characteristics for blunt waverider were also taken into account together. At the same time, Liu proposed the "non-uniform blunt waverider" that improve the aerodynamic performance effectively. Though the influence of bluntness on the performance of waverider configuration has been studied deeply, the hypersonic flight tests were frequently abortive in recent years, such as HTV-2. That is because of the serious aero-heating along leading edge. So, how to reduce the drag and aero-heating effectively is still a key aspect for blunt hypersonic vehicle. There are so many work need to be done about the blunt waverider before its successful application. On the other hand, the opposing jet at the head of blunt body is an effective method to reduce the drag and aero-heating [24]-[30], and Huang [31][32] gave a detailed review on the drag and heat flux reduction induced by the counterflowing jet and its combinations. The blunt waverider geometry in the head is similar with the blunt body, thus, the opposing jet will work in the part of head to achieve the drag and aero-heating reduction. 
In order to improve the aerodynamic performance of blunt waverider, the "non-uniform blunt radii method" will be used in this article. More, the opposing jet will also be used in the waverider with variable blunt radii to improve the aerodynamic performance and aero-heating characteristics deeply. The combination of non-uniform blunt radii method and opposing jet in the waverider is a novel way to make the waverider having the better characteristics. At the same time, the work will achieve a small step for transforming ideal waverider to practical application.

\section{Design approach}

\subsection{The design method for cone-derived waverider}

Waverider configurations have been constructed from axisymmetric flow fields past circular cones based on the theory that Kim and Rasmussen [33] provided. In the paper, the coordinate system and nomenclature are shown in Figure 1, and a parabolic upper surface trailing edge is given, see Eq.1. Then, the leading edge can be obtained along the free flow anti-direction in the shock-wave cone, according to Eq.2, and at last, the trailing edge curve will be generated based on the relationship between $R_{c b}$ and $R_{\infty b}$, see Eq.3. Where, the waverider configuration is decided by the following parameters: Free stream Mach Number(Ma), Semi-vertex shock angle $(\beta)$, Dihedral angle $\left(\phi_{l}\right)$ and Base body length $(l)$. The upper surface is obtained by the rules of being parallel to the free stream. And the lower surface is generated by tracing streamlines from leading edge to the base plane.

$$
\begin{gathered}
X \equiv R_{0}+A Y^{2} \\
Z=\sqrt{X^{2}+Y^{2}} \sqsubset \cot (\beta) \\
R_{c b}^{2}=\left(1+\frac{\sigma^{2}-1}{\sigma^{2}} R_{\infty b}^{2}\right)
\end{gathered}
$$




$$
\sigma \equiv \frac{\beta}{\delta} \square\left[\frac{\gamma-1}{2}+\frac{1}{K_{\delta}^{2}}\right]^{\frac{1}{2}}
$$

According to the above theory, the basic waverider configuration was obtained and is summarized in the Table.1.

\subsection{The variable blunt radii method}

In the article, the traditional blunt method is adopted to modify the leading edge of ideal waverider [36]. Different blunt radii are employed to achieve the blunt waverider with variable radius in the different position. The waverider configurations are classified in three types. Type 1 is the waverider with uniform blunt radius. Type 2 is the waverider with variable blunt radii from the head to back plane. Type 3 is the waverider with different blunt radii from the head to some part away from back plane and then keeping the smaller radius at a uniform value to the back plane, see Figure 2. Herein, Types 2 and 3 are called "Non-uniform Blunt Waveriders" [23].

At the same time, the blunt leading edge is defined according to the blunt radius and the flow field characteristic, see Figure 2. The stagnation point is at the head of waverider, the "nosed zone" is a small zone around the stagnation point, and the "variable blunt radii zone" is in where the radius changes continually and the "uniform radius zone" is the last part of leading edge which is blunt with small radius. The blunt waverider will not only make the manufacture possible, but also improve the aero-heating characteristic of waverider. However, the stagnation point and "nosed zone" will still endure the effect of the high temperature and severe aero-heating. At the "variable blunt radii zone”, the temperature and heat flux will decrease sharply, and the aero-heating will not be obvious. This is called "transition zone" and its area will affect the tradeoff between the aerodynamic and aerothermodynamic characteristics. More, the "uniform radius zone" is useful to sustain the lift characteristic because of its small changes for the ideal waverider. Where, $R$ is the radius of the head and $r$ is the 
minimum radius for the variable blunt waverider. $R$ is the main parameter to influence the aerothermodynamic characteristic and affects the aerodynamic performance, especially the drag rising. Comparing with uniform blunt waverider, $r$ will make up the loss of aerodynamic performance that caused by large blunt radius to some extent.

\subsection{The design approach of blunt waverider with opposing jet}

As we know, the opposing jet is able to change the flow field structure, then improves the aerodynamic characteristic of hypersonic vehicle [37]. In order to reduce the drag and aero-heating performance in the head, the paper adopts the opposing jet to achieve it. According to the variable blunt radii method in the previous part, the aperture jet will be used at the head of waverider to reduce the drag and the aero-heating in the "Nosed zone". There is a different "Nosed zone" for different blunt radius, so the shape of the opposing jet will be designed according to the area of "Nosed zone" and the head blunt radius. The design of aperture jet is shown in Figure 3. Where, the $S_{\text {jet }}$ is the length of jet, and $h$ is the height of jet. $R, r_{0}, r_{1}$ and $r_{2}$ are respectively the radii at the different positions for the blunt leading edge. $L_{0}$ is the length of waverider and $L_{1}$ is the length for the blended blunt radii zone. The geometry for the waverider configuration with variable blunt radii is shown in Figure 4 .

Based on the above methods, the different cases for different Types have been designed and the configuration parameters are listed in the Table 2. Herein, $L_{0}$ equals $l_{\mathrm{w}}$ and its value is $0.6 \mathrm{~m}$.

\section{CFD approach and numerical validation}

\subsection{CFD approach}

The three-dimensional coupled implicit Reynolds Averaged Navier-Stokes(RANS) equations and the two-equation SST $k$ - $\omega$ turbulence model [39][40] have been employed to numerically simulate the aerodynamic 
characteristics which caused by the different blunt waveriders. The turbulence equations of the compressible gas can be described with the appropriate reference frame:

(a) Equation of mass conservation:

$$
\frac{\partial \rho}{\partial t}+\frac{\partial\left(\rho u_{i}\right)}{\partial x_{i}}=0, \quad \mathrm{i}=1,2,3
$$

(b) Equation of momentum conservation:

$$
\frac{\partial}{\partial t}\left(\rho u_{i}\right)+\frac{\partial}{\partial x_{j}}\left(\rho u_{i} u_{j}\right)=-\frac{\partial P}{\partial x_{i}}+\frac{\partial \tau_{i j}}{\partial x_{j}}+F_{b i}, \quad \text { i, j=1, 2, } 3
$$

(c) Equation of energy conservation:

$$
\rho \frac{D}{D t}\left(h+\frac{u^{2}}{2}\right)=\frac{\partial P}{\partial t}+\frac{\partial}{\partial x_{j}}\left(\tau_{i j} \cdot u_{i}\right)-\frac{\partial q_{i}}{\partial x_{i}}+F_{b j} \cdot u_{j}+Q, \quad \mathrm{i}, \mathrm{j}=1,2,3
$$

(d) Equation of turbulent kinetic energy $(k)$ :

$$
\frac{\partial}{\partial x_{i}}\left(\rho k u_{i}\right)=\frac{\partial}{\partial x_{j}}\left(\Gamma_{k} \frac{\partial k}{\partial x_{j}}\right)+G_{k}-Y_{k}+S_{k}, \quad \text { i, j=1, 2, } 3
$$

(e) Equation of the specific dissipation rate $(\omega)$ :

$$
\frac{\partial}{\partial x_{j}}\left(\rho \omega u_{j}\right)=\frac{\partial}{\partial x_{j}}\left(\Gamma_{\omega} \frac{\partial \omega}{\partial x_{j}}\right)+G_{\omega}-Y_{\omega}+D_{\omega}+S_{\omega} \quad \text { i, j=1, 2, } 3
$$

Other equations:

$$
\begin{gathered}
\Gamma_{k}=\mu+\frac{\mu_{t}}{\sigma_{k}} \\
\Gamma_{\omega}=\mu+\frac{\mu_{t}}{\sigma_{\omega}}
\end{gathered}
$$

In these equations, $\rho, u_{i}, P, \tau_{i j}, F_{b i}$, and $Q$ respectively stand for the density, components velocity, pressure, turbulent shearing stress, body force components, and bulk heat treatment. $G_{k}, G_{\omega}, Y_{k}$ and $Y_{\omega}$ are separately the production of turbulence kinetic energy caused by velocity gradients, the dissipation of $k$ and $\omega$ in the compressible turbulent flow and the modulus of the mean strain tensor. $S_{k}, S_{\omega}$ and $D_{\omega}$ are 
user-defined source terms and the cross-diffusion term. $\Gamma_{k}$ and $\Gamma_{\omega}$ represent the effective diffusivity of $k$ and $\omega . \sigma_{k}$ and $\sigma_{\omega}$ are the turbulent Prandtl numbers of $k$ and $\omega$. The viscosity and thermal conductivity are evaluated using a mass-weighted mixing law. The equations are solved along with the density based (coupled) double precision solver of FLUENT [38], and the wall Prandtl number for the turbulence model is set to be 0.85 in order to test its effect on the numerical results. The first order spatially accurate upwind scheme (SOU) with the advection upstream splitting method (AUSM) flux vector splitting is employed to quicken the convergence speed, and the Courant-Friedrichs-Levy (CFL) number is set at 0.2 at first, and then changes in solution steering according to the flow field. The wall is in the no-slip and isothermal boundary conditions and the temperature is set to be 300K. At the outflow, all the physical variables are extrapolated from the internal cells. The standard wall functions are introduced to model the near-wall region flow, and the air is assumed to be a thermally and calorically perfect gas. The solutions can be considered as converged when the residuals reach their minimum values after falling for more than five orders of magnitude, and the difference between the computed inflow and outflow mass flux is required to drop below $10^{-5} \mathrm{~kg} \cdot \mathrm{s}^{-1}$.

At the same time, the computational domain is structured by the commercial software ICEM CFD 14.0 [35], and the grid is multi-blocked and highly concentrated close to the wall surfaces, and the scale for first layer mesh is $10^{-6} \mathrm{~m}$ in order to ensure the accuracy of the numerical simulation that will results in a suitable value of $\mathrm{y}^{+}$for all of flow fields, namely its maximum value is less than 1 . Figure 5 represents the sketch diagram of the grid system for Case 3.

As for the boundary conditions, the inflow boundary is considered the pressure-far-field ${ }^{[37]}$, and the opposing jet is considered the pressure inlet. The specific parameters are as shown in Table 3. The value of $\mathrm{P}_{0 i n} / \mathrm{P}_{0}$ is set to be 0.4 according to the Ref.[37]. 


\subsection{Numerical validation}

In this section, in order to valid the credibility of the numerical methods, the opposing jet model that is derived from the published literature is adopted to verify the numerical method. The experiment data is also from the literature[26].

The results for the numerical simulation are compared with the experimental data, see Figure 6. Figure 6(a) shows the comparison for density gradient contour obtained by CFD and wind tunnel experiment. Figure 6(b) depicts the comparison of Stanton number(St) for numerical and experimental results.

As shown in Figure.6(a), it is obvious that the predicted shock wave stand-off distance is slightly larger than that obtained in the experiment. This discrepancy may be induced by the symmetric solver and turbulence model. However, the locations of Mach disk and the triple point are nearly the same. The $S t$ for numerical result is lower than that of experimental data when $\theta$ is not beyond $38.5^{\circ}$, and the same trend can be obtained when $\theta$ is beyond $54.5^{\circ}$. And the $S t$ for numerical simulation is bigger than that of experimental data between the two angles. More, the variable trend of predicted St distribution is the same as that obtained by the experiment in recirculation region, and the positions of peak heat flux are the same, see Figure 6(b). The difference of maximum St is $10 \%$. This implied that the heat flux in the supersonic flow can be obtained by the commercial software Fluent. This phenomenon may be caused by the differences of their cooling gases and model coefficients.

From the above discussion, the numerical results show good agreement with the experimental data. We may safely draw the conclusion that the numerical method in the paper can simulate the opposing jet field well in supersonic flow, and the numerical results are believable in the following discussions. 


\section{Results and discussion}

In this part, the mechanism of bluntness impact on the aerodynamic and aero-heating performance is studied based on the variable blunt method. At the same time, the influence of aperture on the drag and aero-heating reduction for blunt waverider is also investigated in this article.

In order to obtain a detailed study on the influence of opposing jet on the blunt waverider, five slices and curves in the vertical direction of flow are chosen to discuss the flow field characteristics, see Figure 9(a). The positions for different slices and curves along $\mathrm{X}$ direction are respectively $0.411,0.412,0.41337,0.445$ and 0.7 . The beginning point of blunt leading edge $(\mathrm{x} 0)$ is 0.41054 , and the ending point of the aperture in the flow direction is 0.41337 . At the same time, the ending position of variable blunt radius in the flow direction is 0.445 . More, the flow characteristics in symmetry plane are also discussed, and the detailed information is as followings.

Figure 7 shows the aerodynamic characteristics for different cases, and the information of all cases are listed in Table 2. The lift coefficients of Case 1 and Case 3 are larger than that of Case 2, and the value of Case 4 is smaller, see Figure 7(a). More, the drag coefficient of Case 1 is smaller than that of Case 2, and the value of Case 3 is almost the same with that of Case 2. The drag coefficient of Case 4 is the smallest among all cases, see Figure 7(b). The $L / D$ of Case 1 is the largest and it will drop 7 8\% when $R$ changes from $2 \mathrm{~mm}$ to $8 \mathrm{~mm}$. Because the bow shock wave becomes more obvious, the drag increases. At the same time, the area of compression surface decreases with the increase of $R$, the lift decreases. More, the $L / D$ of Case 3 is larger than that of Case 2 and this implies that the variable blunt radii method is very useful for the improvement of aerodynamic characteristics. In addition, based on the comparison between cases 3 and 4, the lift and drag characteristic for the waverider with opposing jet is smaller, and the extent of drag reduction is larger when the opposing jet is used in blunt waverider, so the $L / D$ will increase. This phenomenon shows that the aperture can improve the 
aerodynamic performance of blunt waverider. At the same time, the combination of variable blunt radii method and the opposing jet for blunt waverider can make its $L / D$ improve $4 \sim 5 \%$, and the $L / D$ is 5.91 , see Figure 7 (c). This shows that the opposing jet is also useful for the blunt waverider.

Figure 8 shows the flow field characteristic analysis along the stagnation line. Herein, $R 8, R 8(r 2)$ and $R 8$ (r2-jet) are respectively cases 2,3 and 4 . The shock compression of variable blunt radii waverider is a little stronger than that of uniform blunt radius waverider when $R$ keeps the same. The distance of detached shock wave of Case 4 will increase obviously, and the trend of Mach number behind shock wave is 'decrease-sharplyincrease-decrease' along the stagnation line. When the Mach number increases, the value will be beyond 1 . That is because the static temperature is lower in this region, and the sound velocity is lower. More, the Mach number of Case 4 is near zero at $X=0.408$, and this shows that the velocity is near zero in this position, see Figure 8(a-b). In addition, there is a low temperature region along stagnation line near the aperture, and the recirculation region in where the temperature is lower also exists around the aperture, see Figure 8(b). And the phenomenon will reduce the aero-heating and improve the aerothermodynamic environment effectively. The ability of shock wave compression is the same at the same flow condition, so the max static pressure behind the shock wave is almost the same and the value is near $110 \mathrm{KPa}$ that is 43.8times of flow static pressure. The static pressure increases sharply near the aperture, see Figure 8(c). That is because the static pressure of the jet is very high.

Figure 9 shows the comparison of pressure distribution along different curves for different cases. There are different pressure distributions for different cases on the same slice. The pressure of case 3 is a little lower than that of case 2 at $X=0.411$ and their trends are almost the same at $X=0.412$, see Figure $9(\mathrm{~b}-\mathrm{c})$. However, the pressure of case 3 is a little higher than that of case 2 at $X=0.41337$, see Figure $9(\mathrm{~d})$. These phenomena show that the blunt method has the obvious influence on the pressure. The influence of aperture on the pressure is very obvious at $X=0.411$ and the pressure of case 4 is much lower than that of cases 2 and 3 . And the similar results can be obtained at $X=0.412$ and 0.41337 . These phenomena show that there are the recirculation regions and low 
pressure regions in the upper and lower surfaces near the aperture. The effect of $R$ on the pressure distribution is obvious, see Figure 9(e). At the same time, the pressure is higher than those of other two cases in the upper and lower surfaces when $X$ is 0.445 . That is because the detached shock wave reattaches the surfaces and the reattachment point of shock wave behind the recirculation region appears in the near region. To some extent, we can know the recirculation region's area. In addition, the pressure distribution at $X=0.7$ is similar for different cases.

In order to know the flow field characteristics better, the contours for the different flow parameters of cases 3 and 4 on the different planes are chosen to discuss the detail information of flow field.

Figure 10 shows the contours of different flow parameters on the symmetry plane, respectively $M a, T_{\mathrm{e}}$ and $P_{\mathrm{e}}$. The position of detached shock wave for case 4 is farther than that of case 3 obviously, see Figure 10(a). More, the high temperature and pressure zone of case 4 is far away from the body, and this will result in the decrease of the heat flux in the wall and improve the aerothermodynamic environment. There is the optimal $P_{0 \text { in }} / P_{0}$ that can make the detached shock wave reattach the compression surface again so that the blunt waverider can get the better aerodynamic performance, see Figure 10(b-c). Figure 11 shows the Mach number contour comparison of Cases 3 and 4 for different slices. The influence of opposing jet on the flow field is very obvious, especially at the position of aperture. The effect region of opposing jet decreases continually along $X$ direction. There are the low Mach number regions near the upper and lower surfaces when the opposing jet is used in the blunt waverider. However, the phenomena do not appear in case 3. These phenomena also validate that the recirculation region truly exists in the whole flow field. The flow field is almost symmetry based on the center plane of the aperture and the aperture can improve the aerodynamic and aerothermodynamic characteristics by changing the flow field structure, see Figure 11 and Figure 7-8.

Figure 12 shows the comparison of pressure distribution for cases 2, 3 and 4 on the blunt surface. Although the $R$ is the same, the different blunt method has different pressure distribution on the blunt surface. The high 
pressure region of case 3 is larger than that of case 2, and their high pressure regions both appear at the nosed zone, see Figure 12. The opposing jet can change the flow field structure at the nosed zone and improve the aerothermodynamic environment in the whole flow field. The variable blunt radii method is a good way that is used to improve the aerodynamic and aerothermodynamic characteristics of blunt waverider. And the aperture is also a novel way to improve the whole characteristics of blunt waverider. So this will be one solid step that making the ideal waverider to practicality.

\section{Conclusions}

In this article, we adopt the variable blunt radii method to modify the ideal waverider, and then add the opposing jet to the blunt waverider and the aperture is used to improve the waverider characteristics. According to the research, we have come to the following conclusions:

- The ability of shock wave compression is the same at the same flow condition and the max static pressure behind the shock wave is almost the same and the value is near 110KPa that is 43.8times of flow static pressure.

- The $L / D$ of Case 1 is the largest and it will drop 7 8\% when $R$ changes from 2 to 8 . The lift coefficient will increase and the drag coefficient almost keeps the same when the variable blunt radii method is adopted, and the $L / D$ will increase, at the same time, the high pressure region will augment.

- The variable blunt radii method is very useful to improve the whole characteristics of blunt waverider and the $L / D$ can improve 3\%. The opposing jet can change the flow field structure around the nosed zone and improve the aerothermodynamic environment in the whole flow field. There is the optimal $P_{0 \text { in }} / P_{0}$ that can make the detached shock wave reattach the lower surface again so that the blunt waverider can get the better aerodynamic performance. 
- The combination of the variable blunt radii method and opposing jet is a novel way to improve the whole performance of blunt waverider, and $L / D$ can improve $4 \sim 5 \%$. The aperture as a novel way of opposing jet is suitable for blunt waverider and also useful to improve the aerodynamic and aerothermodynamic characteristics of waverider in the hypersonic flow.

\section{Acknowledgements}

The authors would like to express their thanks for the support from the Science Foundation of the National University of Defense Technology (Grant No.JC14-01-01), and Foundation of Hunan Province (Grant No. CX2013A001).

\section{References}

[1]. Nonweiler, T. R. F., Aerodynamic Problems of Manned Space Vehicles, Journal of the Royal Aeronautical Society, Vol. 63, Sept. 1959, pp. 521-528.

[2]. W. Huang, L. Ma, Z. G. Wang, M. Pourkashanian, D. B. Ingham, S. B. Luo, J. Lei. A parametric study on the aerodynamic characteristics of a hypersonic waverider vehicle. Acta Astronautica, 69(2011) 135-140

[3]. D. Kuchemann, The Aerodynamic Design of Aircraft, Pergamon Press, 1978.

[4]. Lewis M J. Application of Waverider-Based Configurations to Hypersonic Vehicle Design[C].AIAA 91-3304; 1991.

[5]. D.R. Stevens, “Practical Considerations in Waverider Applications,” AIAA Paper No. 4247 (1992).

[6]. D.J. Tincher and D.W. Burnett, "Hypersonic Waverider Test Vehicle: a Logical Next Step,” J. Spacecraft Rock. 31, 392 (1994).

[7]. J.W. Haney, “A Waverider Derived Hypersonic X-Vehicle,” AIAA Paper No. 6162 (1995).

[8]. L. Rudd and D.J. Pines, "Dynamic Control of Mission Oriented Hypersonic Waveriders,” AIAA Paper No. 4951(1999). 
[9]. P.M. Shripad, Theoretical aerothermal concepts for configuration design of hypersonic vehicles, Aerospace Science and Technology 9 (8) (2005) 681-685.

[10].R.P. Starkey, Design of Waverider Based Re-entry Vehicles, AIAA 2005-3390, 2005.

[11].W. Huang, M. Pourkashanian, L. Ma, D. B. Ingham, S. B. Luo, Z. G. Wang. Investigation on the flameholding mechanisms in supersonic flows: backward-facing step and cavity flameholder. Journal of Visualization, 14(2011): 63-74

[12].Wilson F.N. Santos, Bluntness Impact on Lift-to-Drag Ratio of Hypersonic Wedge Flow[J]. Journal of Spacecraft and Rockets, Vol. 46, No.2, March-April 2009.

[13].M.J. Gillum, M.J Lewis. Experimental results on a Mach 14 waverider with blunt leading edges. J Aircraft 1997;34(3):296-303.

[14].Cao DY, Li CX. A numerical study on aerothermodynamic performances of a waverider based vehicle. J Astronaut 2008;29(6):1782-5 [in Chinese].

[15].Santos W F N. Leading Edge Thickness Impact on Drag and Lift in Hypersonic Wedge Flow [C]: 45th AIAA Aerospace Sciences Meeting and Exhibit. Reno, Nevada: 2007.

[16]. Santos W F N. Bluntness Impact on Lift-to-drag Ratio of Hypersonic Wedge Flow[J]. Journal of Spacecraft and Rockets, 2009; 46(2), 329-339.

[17].Chen XQ, Hou ZX, Liu JX, Gao XZ. Modification impact on aerodynamic performance of hypersonic waverider. Aeronautic Journal, 2011;115(1168):325-34.

[18].Chen XQ, Hou ZX, He LT, Liu JX. Multi-object optimization of waverider generated from conical flow and osculating cone. AIAA 2008-131; 2008.

[19].R.P. Starkey. Design of waverider based re-entry vehicles. AIAA 2005-3390, 2005.

[20].D.O. Vanmol, J.D. Anderson. Heat transfer characteristics of hypersonic waveriders with an emphasis on leading edge effects. AIAA-92-2920; 1992.

[21].Liu Jian-Xia, Hou Zhong-Xi, Ding Guo-hao, Chen Xiao-qing, Chen Xiao-qian. Numerical and experimental study on waverider with blunt leading edge [J]. Computers \& Fluids, 84(2013): 203-217.

[22].Jian-Xia Liu, Zhong-Xi Hou, Xiao-qing Chen, Jun-tao Zhang. Experimental and numerical study on the aero-heating characteristics of blunted waverider[J]. Applied Thermal Engineering, 51(2013): 301-314.

[23].Liu Jian-Xia. Study on the Aerodynamic and Aero-heating Basic Problems of Hypersonic Non-uniform Blunt Waverider[D]. National University of Defense Technology, 2013.

[24]. O.D. Endwell, B Warren, O. H. James. Prediction of drag reduction in supersonic and hypersonic flow with 
counter flow jets[R]. AIAA paper, 2002-5115.

[25].Hayashi K, Aso S. Effect of pressure ratio on aerodynamic heating reduction due to opposing jet[R]. AIAA 2003-4041, 2003.

[26]. Hayashi K, Aso S, Tani Y. Numerical study of thermal protection system by opposing jet[R]. AIAA 2005-188, 2005.

[27].Y.S. Rong, Drag reduction research in supersonic flow with opposing jet, Acta Astronaut. 91 (2013) 1-7.

[28]. Hayashi K, Aso S, Tani Y. Experimental study on thermal protection system by opposing jet in supersonic flow [J]. Journal of Spacecraft and Rockets, 2006, 43(1):233-235.

[29]. Chen L W, Wang G L, Lu X Y. Numerical investigation of a jet from a blunt body opposing a supersonic flow [J]. Journal of Fluid Mechanics, 2011, 684: 85-110.

[30].Kentaro Hayashi, Shigeru Aso, Yasuhiro Tani. Numerical Study of Thermal Protection System by Opposing Jet[C]. 43rd AIAA Aerospace Sciences Meeting and Exhibit.2005, Reno, Nevada.

[31].Wei Huang, Yan-ping Jiang, Li Yan, Jun Liu. Heat flux reduction mechanism induced by a combinational opposing jet and cavity concept in supersonic flows[J]. Acta Astronautica, 121(2016) 164-171.

[32]. Wei Huang, Jun Liu, Zhi-xun Xia. Drag reduction mechanism induced by a combinational opposing jet and spike concept in supersonic flows[J]. Acta Astronautica, 115(2015) 24-31.

[33].B.S. Kim, M.L. Rasmussen and M.C. Jischke. Optimization of Waverider Configurations Generated from Axisymmetric Conical Flows[J]. AIAA $9^{\text {th }}$ Atmospheric Flight Mechanics Conference, San Diego California, 1982.

[34].Shibin Li, Rene Steijl, George N. Barokos, Wei Huang, Zhen-guo Wang. Computational analysis of waveriders with variable leading blunt radii[J]. Aerospace Science and Technology. 2015. Under review.

[35].Rene Steijl, George N.Barakos, Sliding mesh algorithm for CFD analysis of helicopterrotor fuselage aerodynamics, Int. J. Numer. Meth. Fluids 58 (2008),527-49.

[36]. Chen XQ, Hou ZX, Liu JX, Gao XZ. Bluntness impact on performance of waverider. Comput Fluids 2011;48(1):30-43.

[37]. Shibin Li, ZhenGuo Wang, Wei Huang, Jun Liu. Effect of the injector configuration for opposing jet on the drag and heat reduction[J]. Aerospace Science and Technology. 2016, 4(51):78-86.

[38]. ANSYS Inc. ANSYS Fluent Use’s Guide, Release 15.0, November 2013.

[39]. Wei Huang, Wei-dong Liu, Shi-bin Li, Zhi-xun Xia, Jun Liu, Zhen-guo Wang. Influences of the turbulence model and the slot width on the transverse slot injection flow field in supersonic flows[J]. Acta Astronautica, 
73(2012) 1-9.

[40].Wei Huang, Li Yan, Jun Liu, Liang Jin, Jian-guo Tan. Drag and heat reduction mechanism in the combinational opposing jet and acoustic cavity concept for hypersonic vehicles[J]. Aerospace Science and Technology, 2015, 42 : 407-414 


\section{Figure caption}

Figure 1 Cone-derived waverider theory and coordinate system

Figure 2 Different zones for the blunt leading edge

Figure 3 Design method of opposing jet for the variable blunt radii waverider

Figure 4 Waverider configurations with variable blunt radii

Figure 5 Sketch diagram of the grid system for Case 3

Figure 6 Comparison between predicted results and experimental data

Figure 7 Comparison of aerodynamic characteristics for different cases

Figure 8 Flow field characteristics analysis along the stagnation line

Figure 9 Comparison of pressure distribution along different curves for different cases

Figure 10 Contours of different flow parameters for cases 3 and 4 on the symmetry plane

Figure 11 Comparison of Ma contour for cases 3 and 4 on different slices

Figure 12 Comparison of pressure distribution for cases 2, 3 and 4 on the blunt surface 


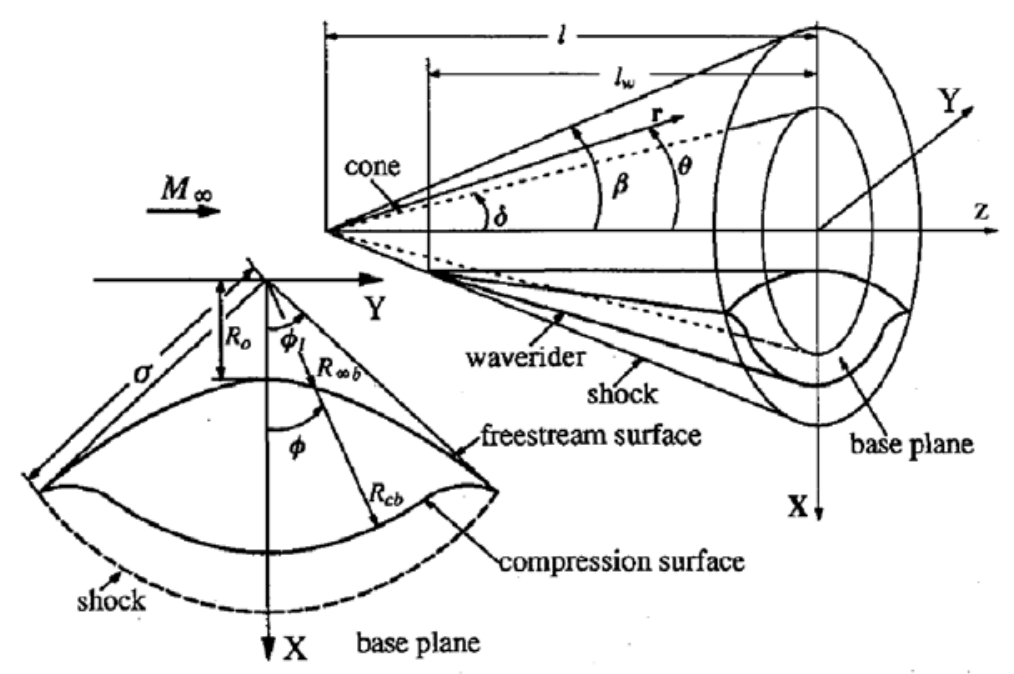

Figure 1 Cone-derived waverider theory and coordinate system 


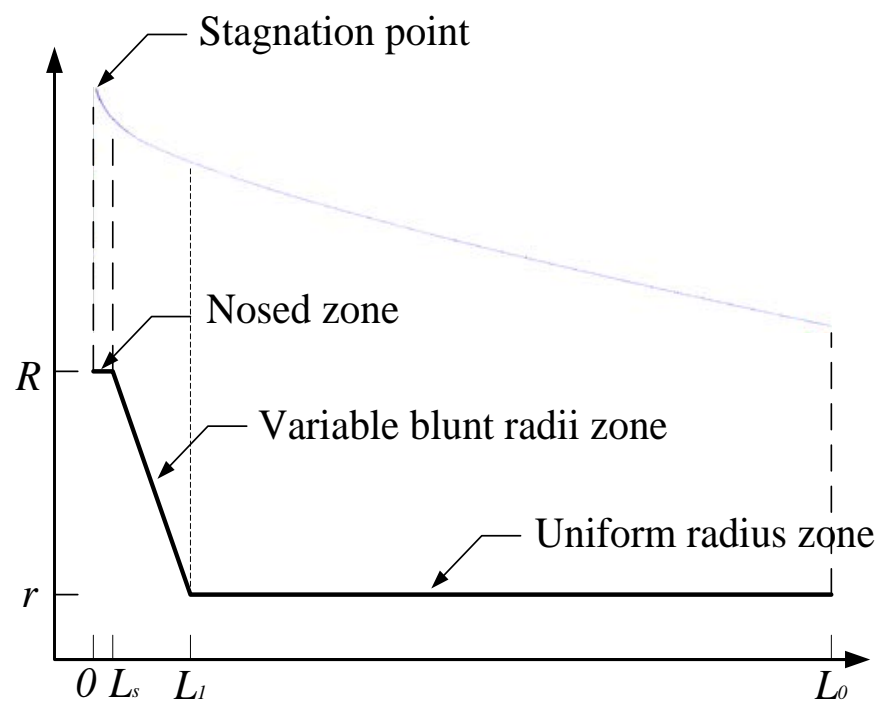

Figure 2 Different zones for the blunt leading edge 


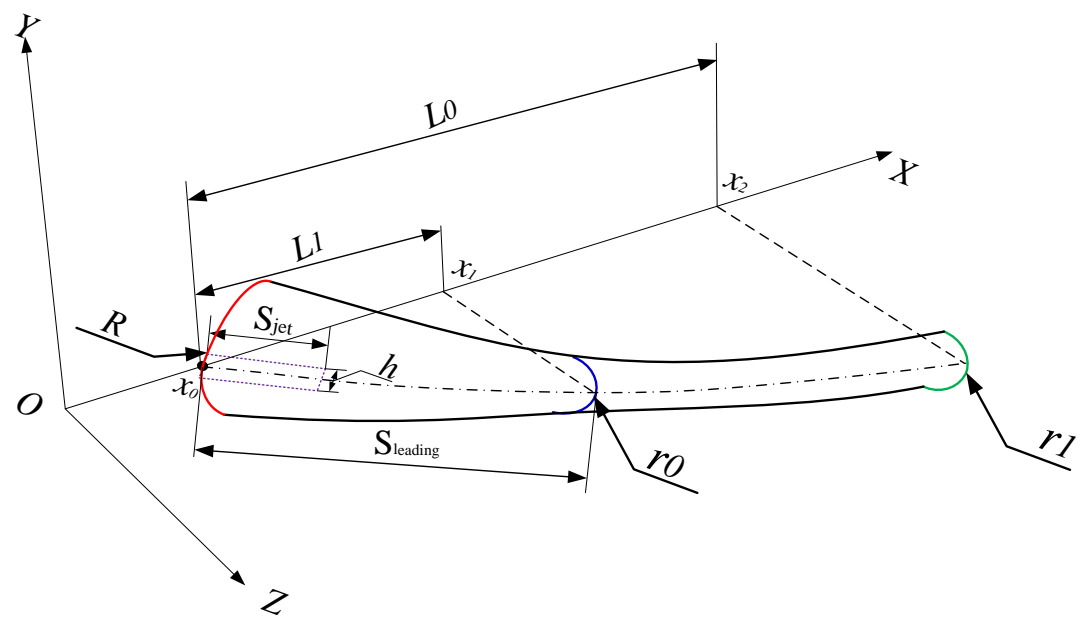

Figure 3 Design method of opposing jet for the variable blunt radii waverider 


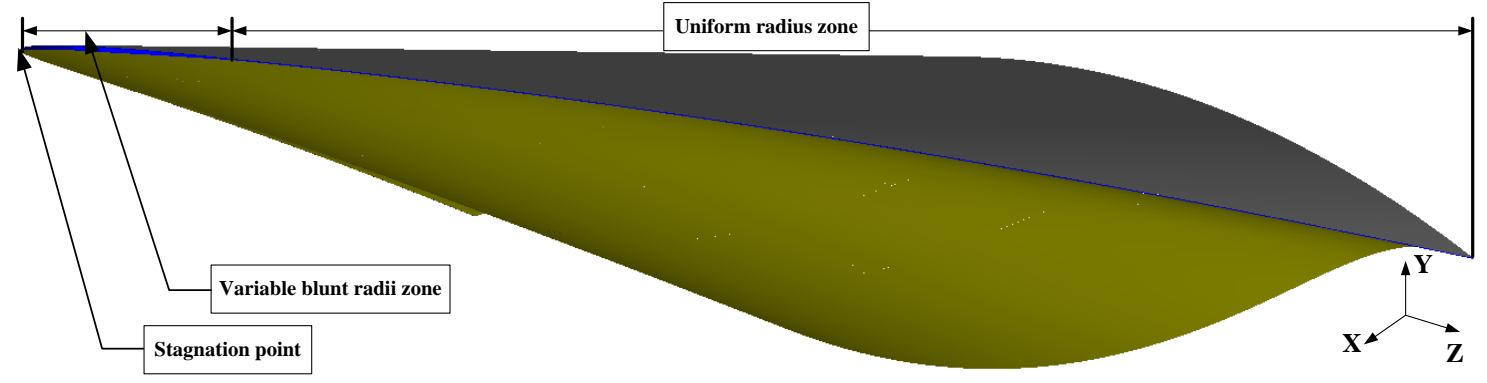

Figure 4 Waverider configurations with variable blunt radii 


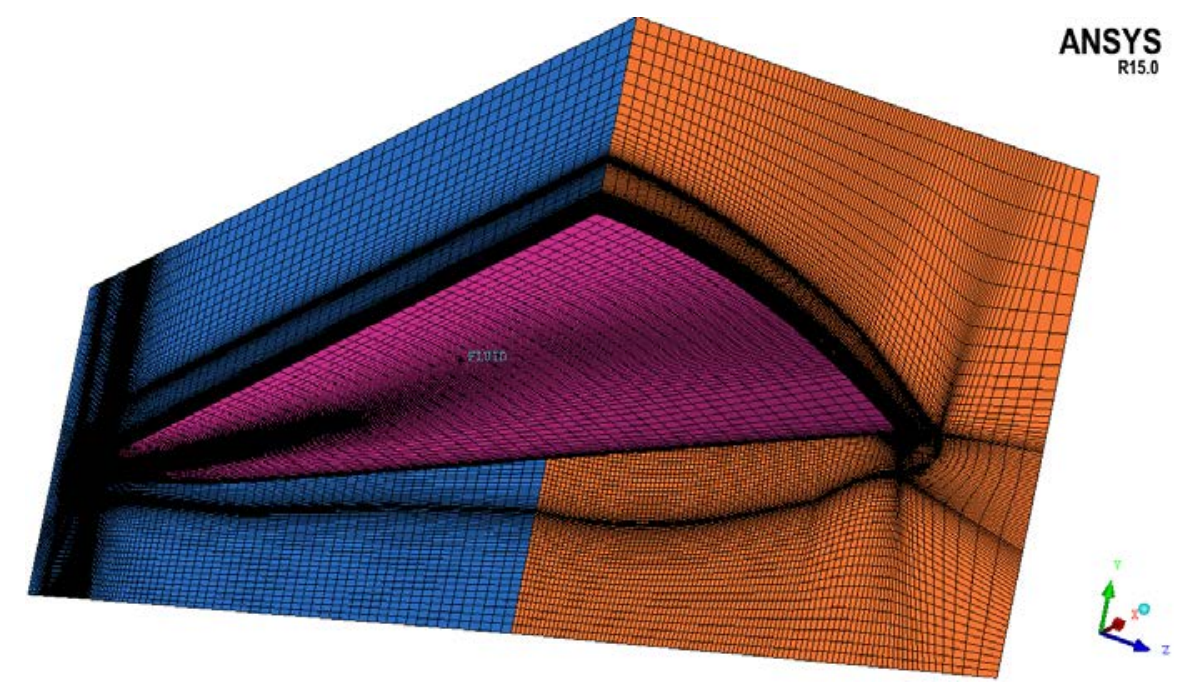

Figure 5 Sketch diagram of the grid system for Case 3 


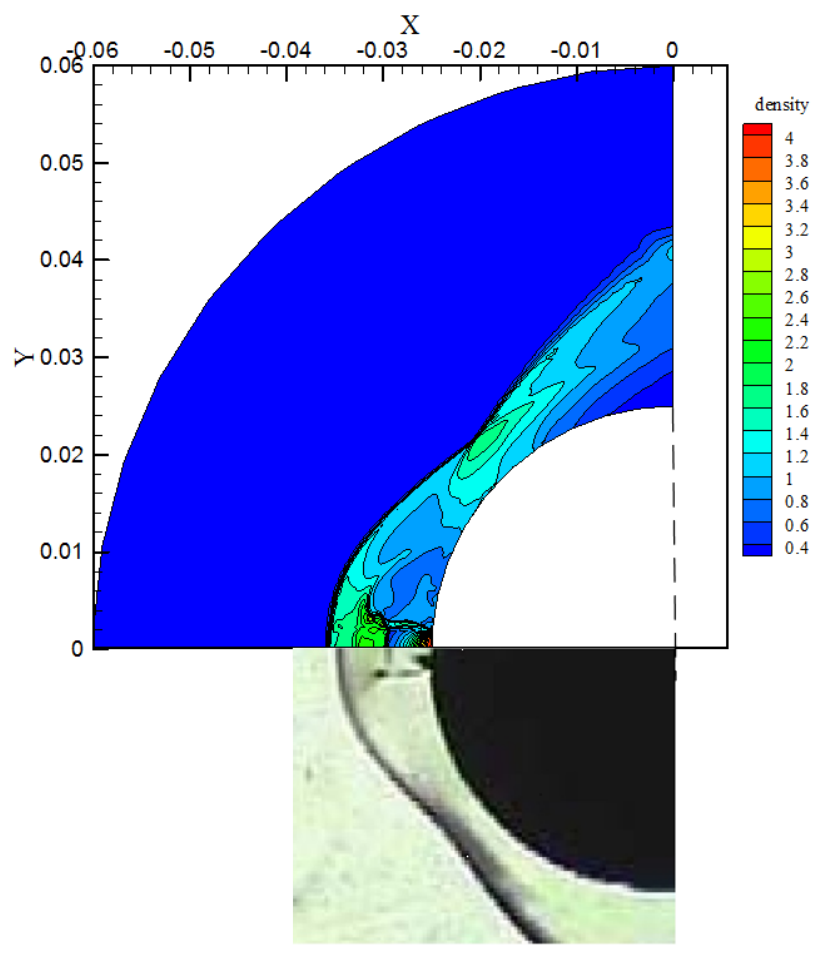

(a) Density

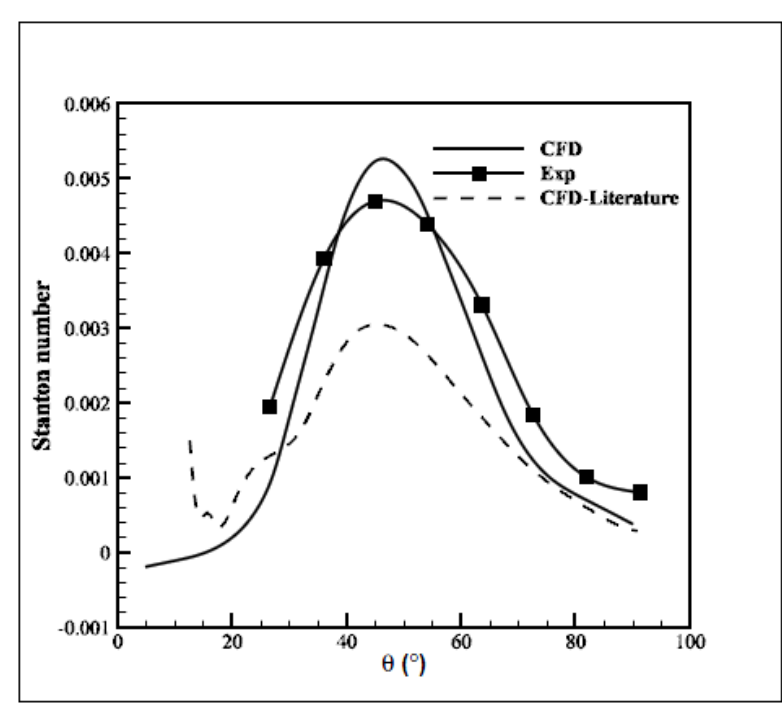

(b) Stanton number

Figure 6 Comparison between predicted results and experimental data 


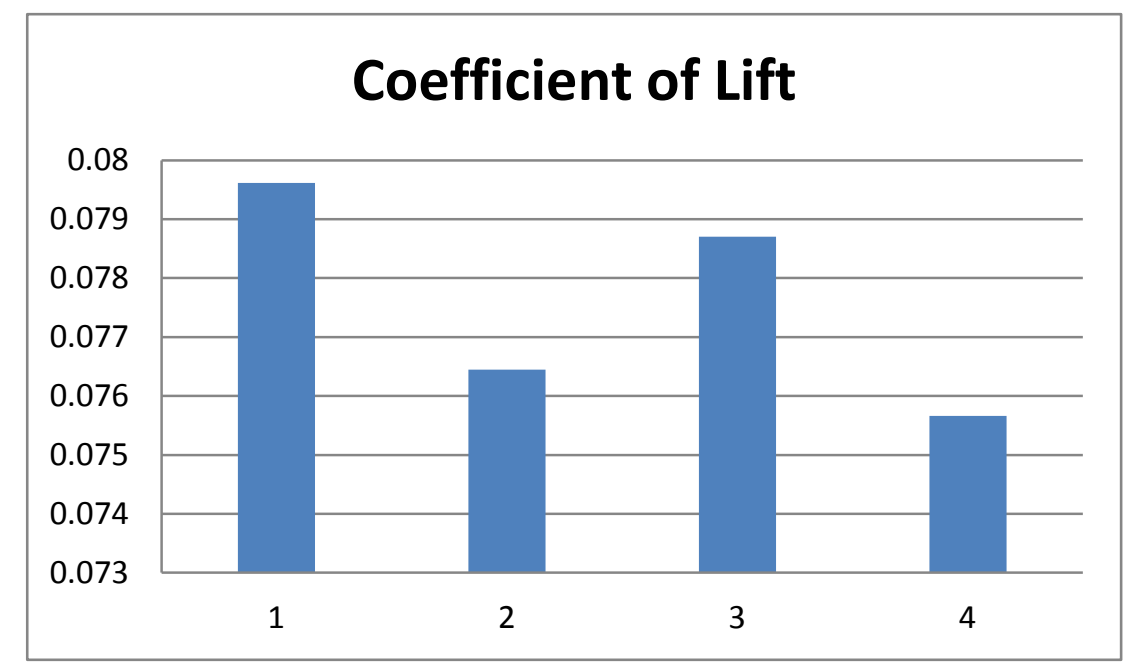

(a) Coefficient of Lift

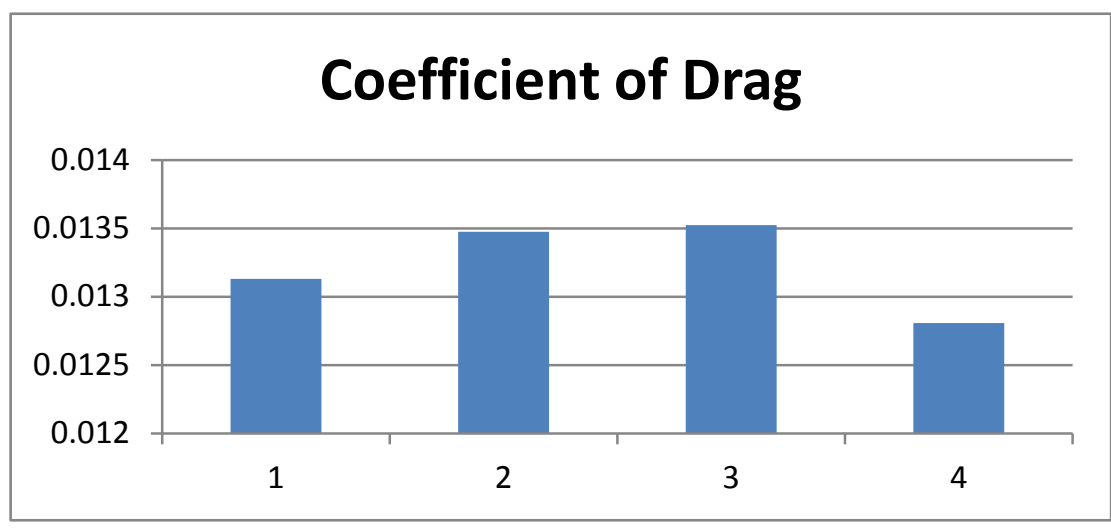

(b) Coefficient of Drag

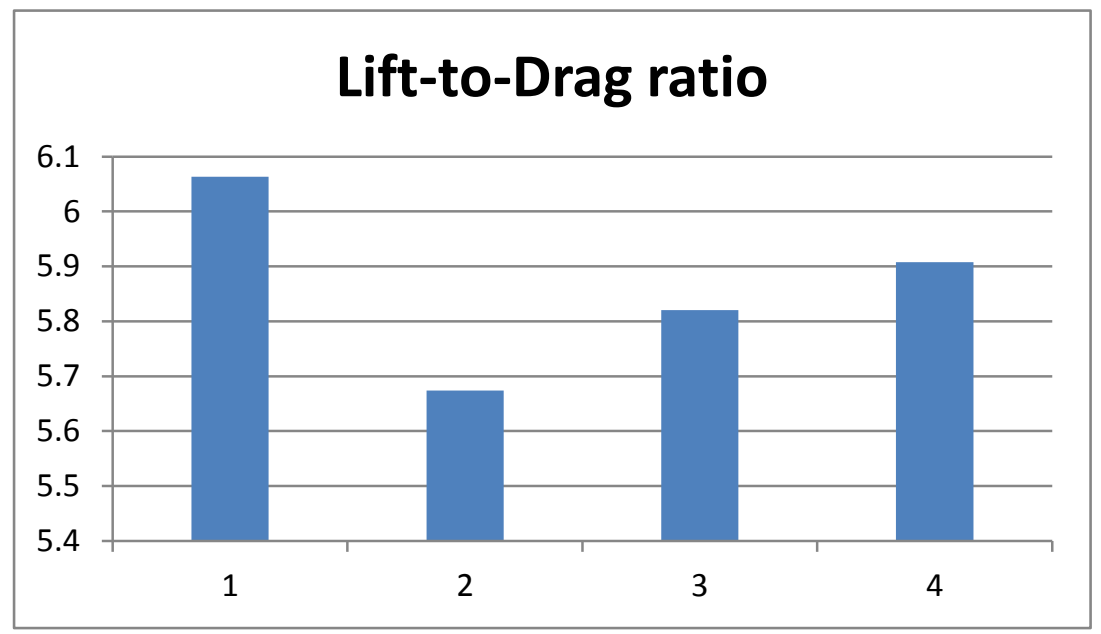

(c) Lift-to-Drag ratio

Figure 7 Comparison of aerodynamic characteristics for different cases 


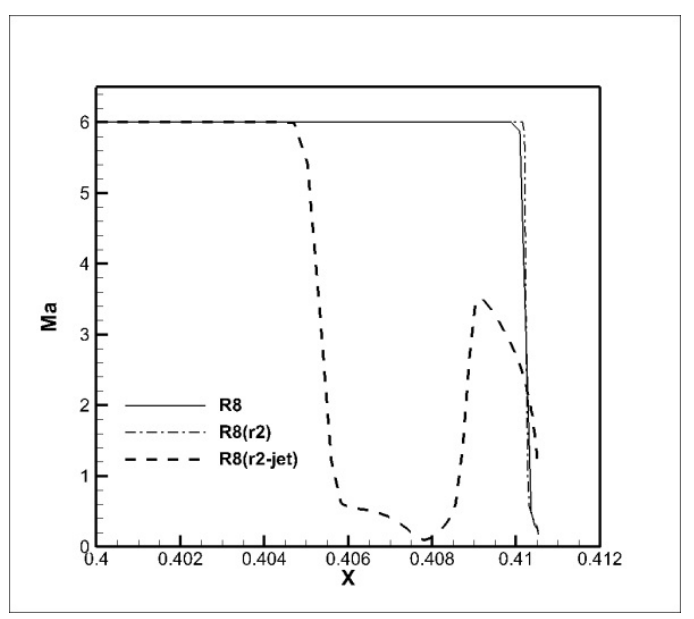

(a) Ma

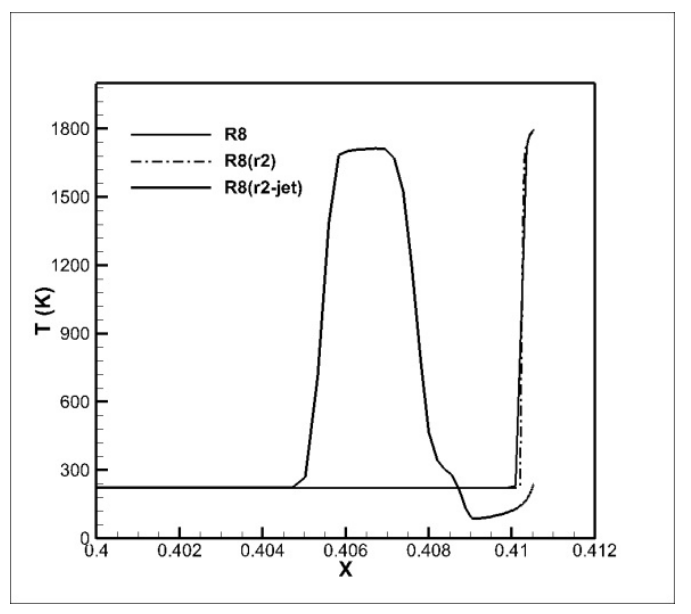

(b) Static temperature

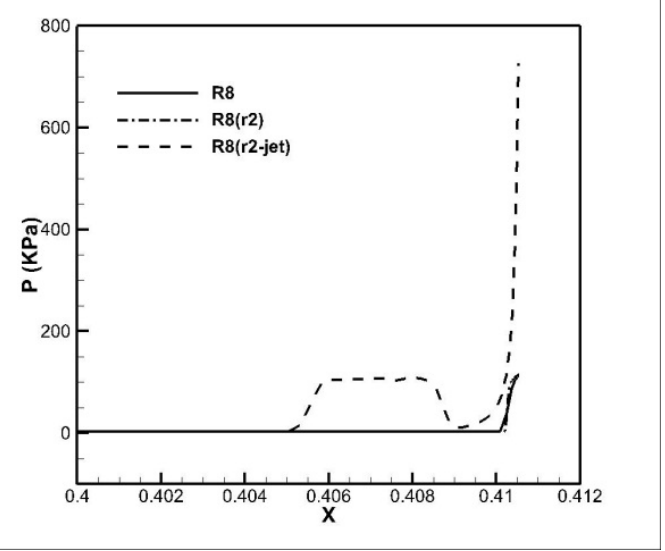

(c) Static pressure

Figure 8 Flow field characteristics analysis along the stagnation line 


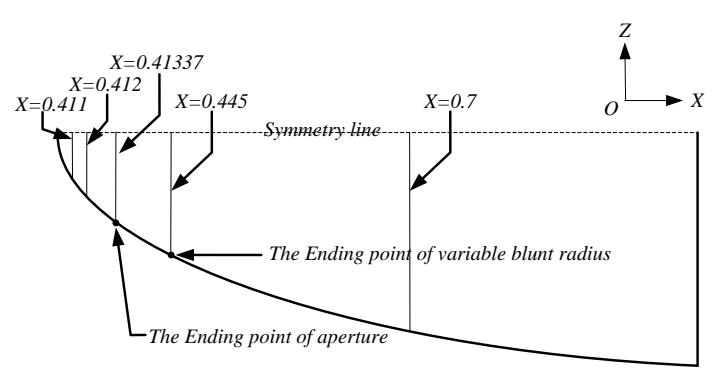

(a) Sketch of chosen sections

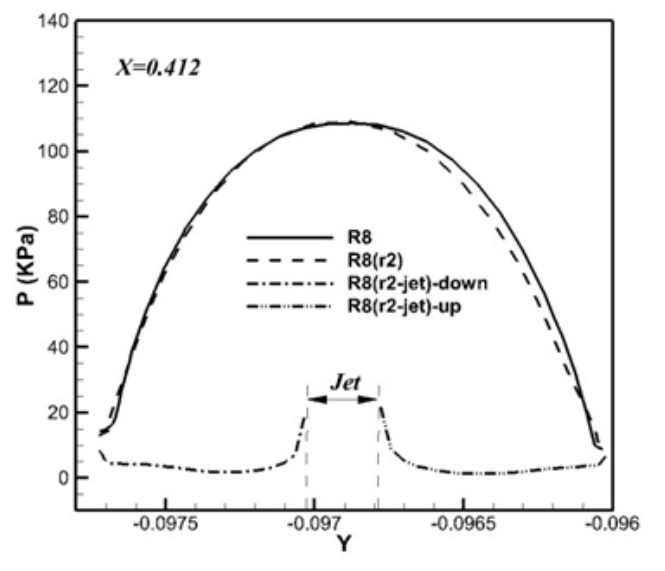

(b) $X=0.412$

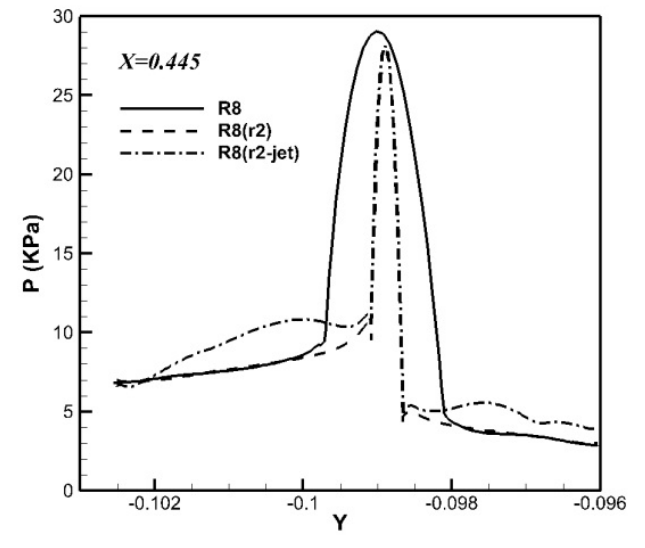

(e) $\mathrm{X}=0.445$

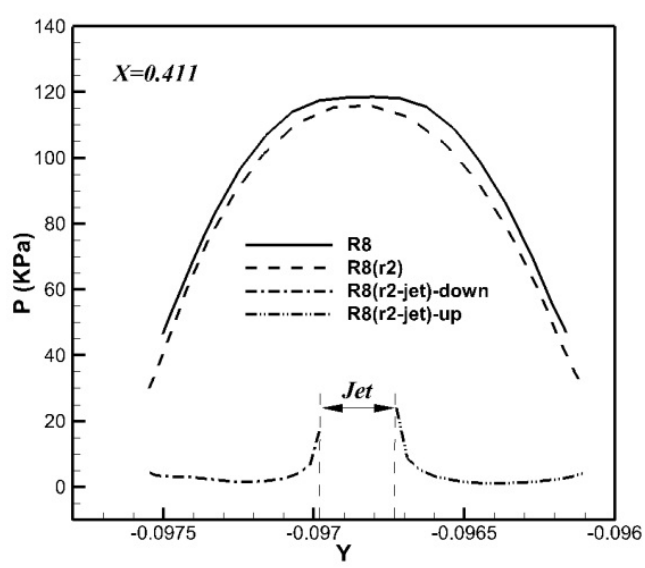

(b) $X=0.411$

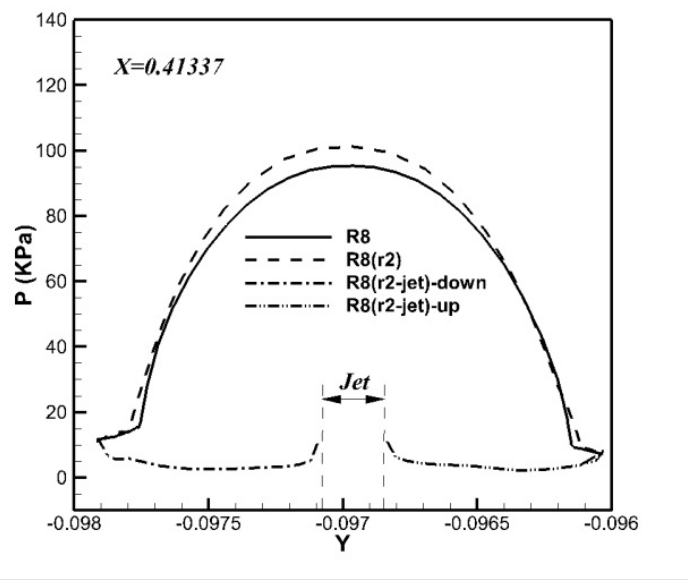

(d) $X=0.41337$

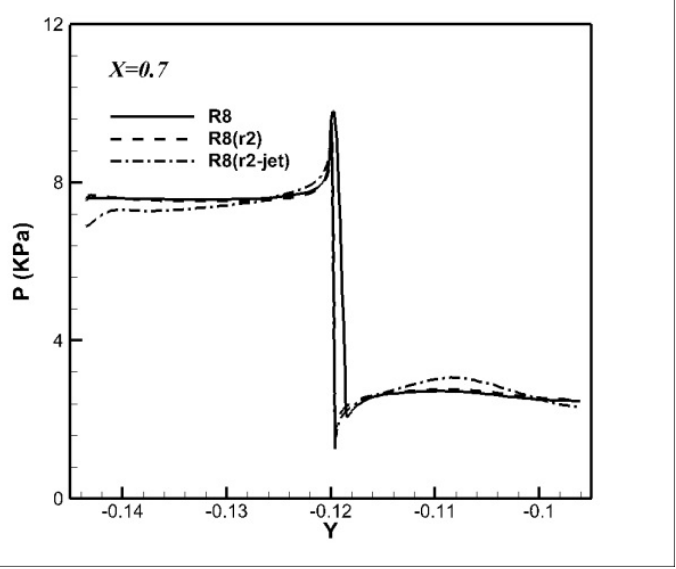

(f) $X=0.7$

Figure 9 Comparison of pressure distribution along different curves for different cases 


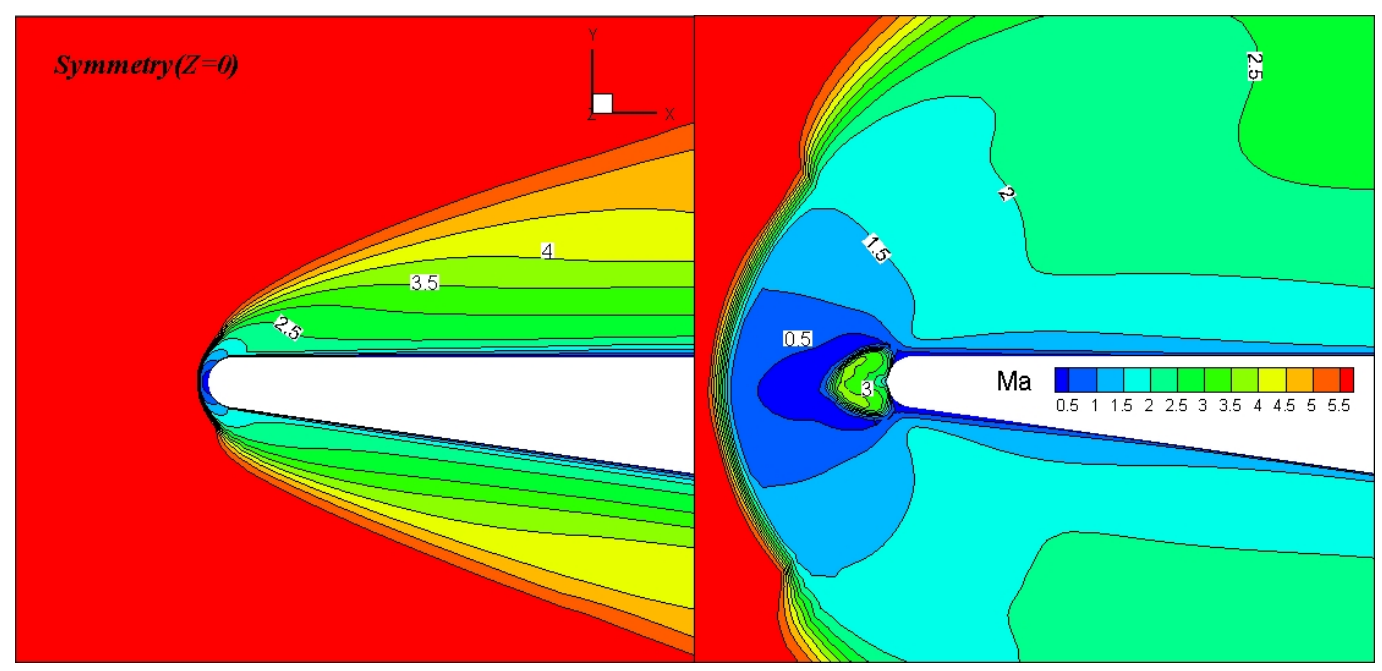

(a) $\mathrm{Ma}$

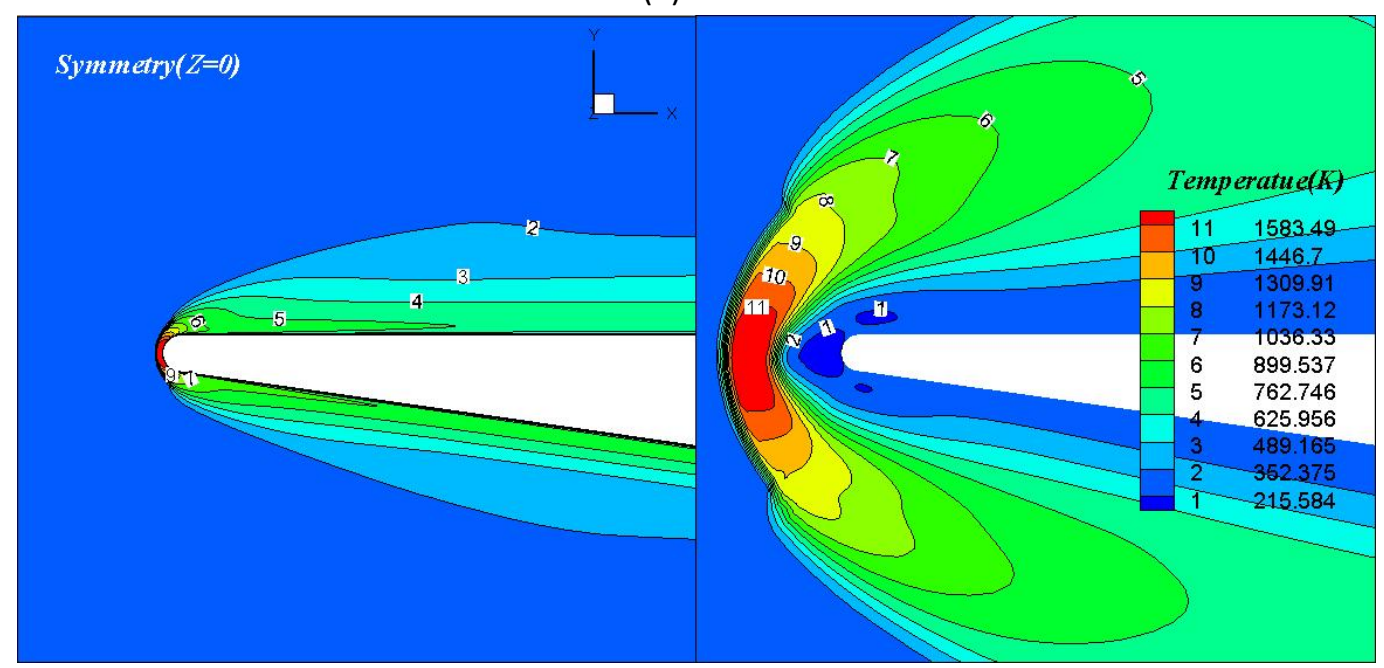

(b) Static temperature

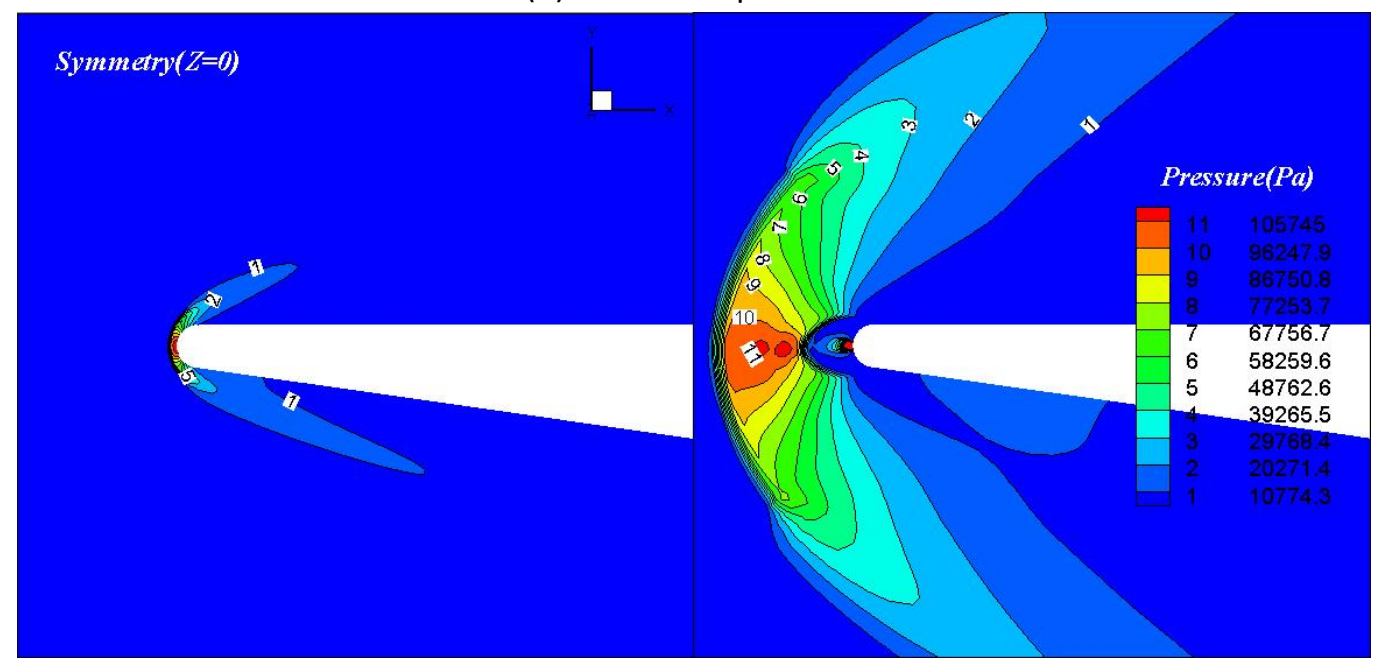

(c) Static pressure

Figure 10 Contours of different flow parameters for cases 3 and 4 on the symmetry plane 


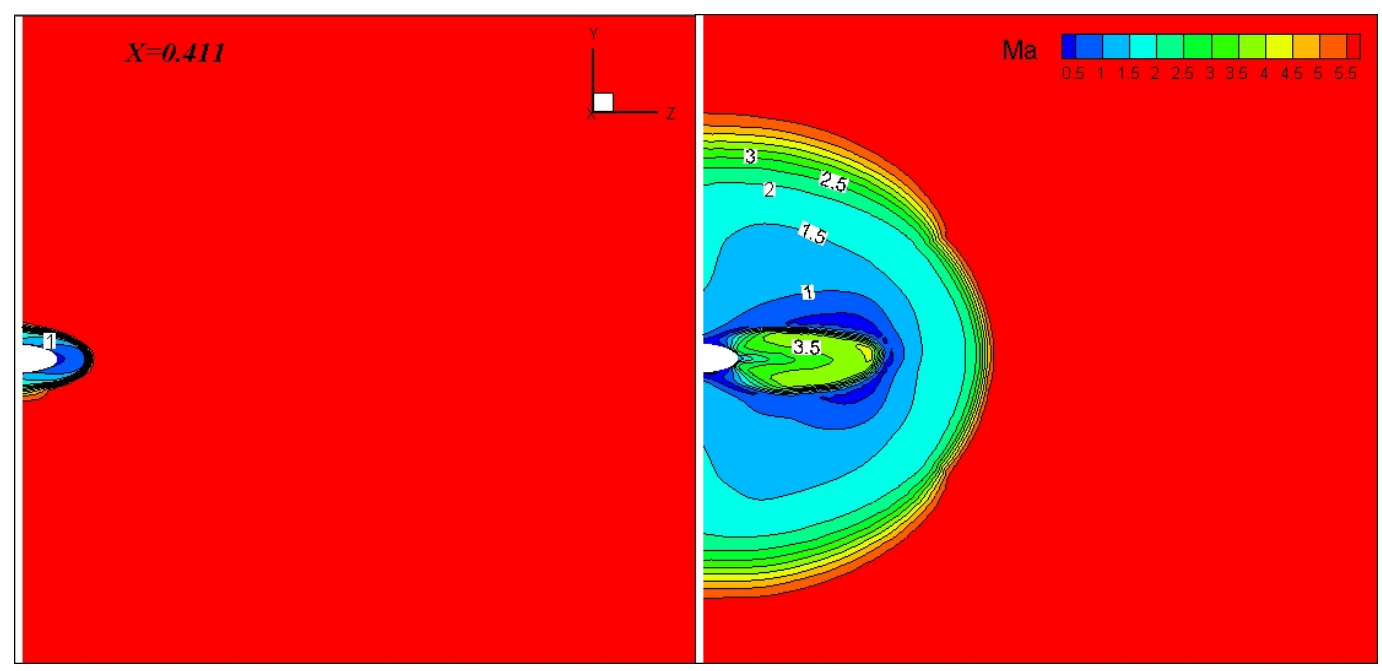

(a) $\mathrm{X}=0.411$

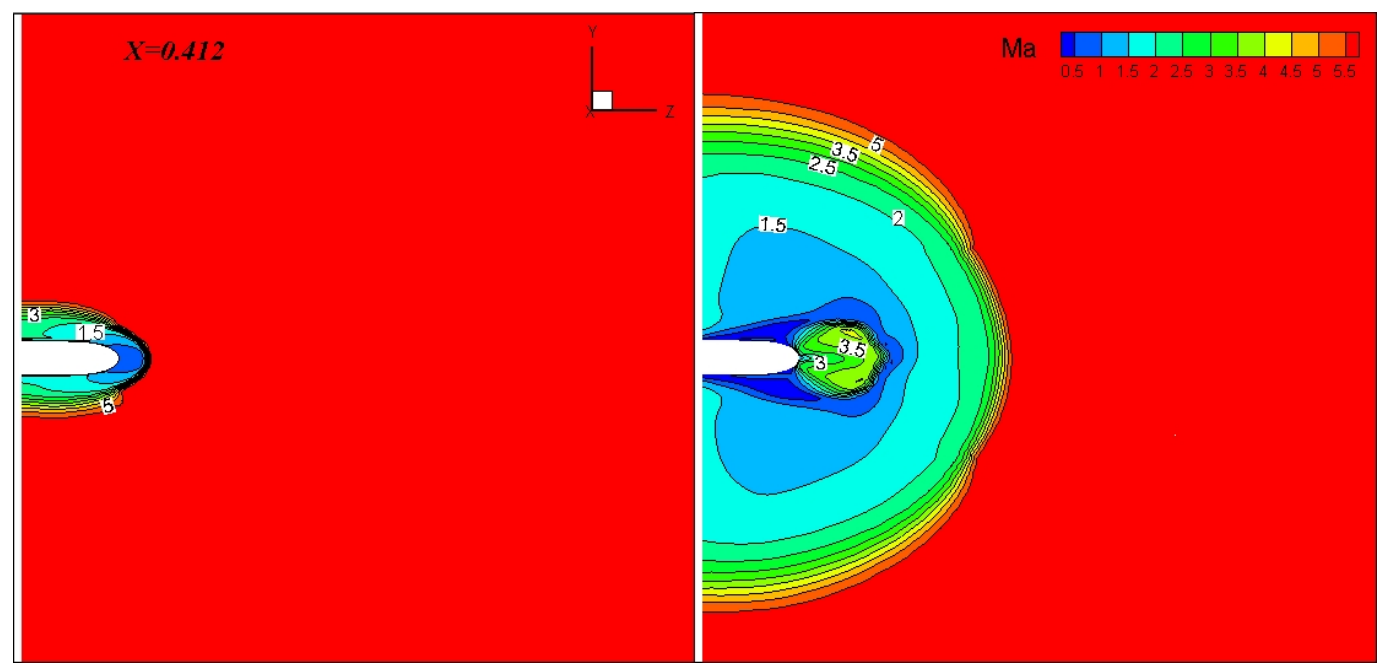

(b) $\mathrm{X}=0.412$

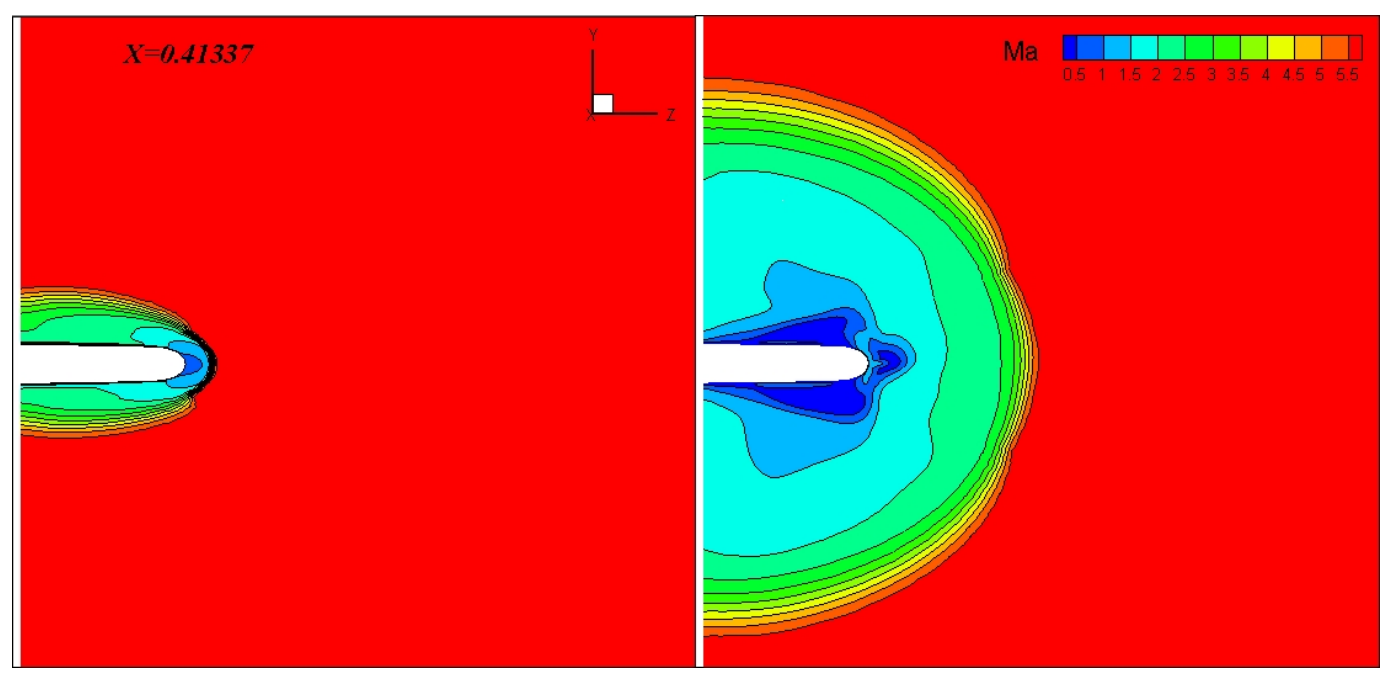

(c) $\mathrm{X}=0.4337$

Figure 11 Comparison of Ma contour for cases 3 and 4 on different slices 

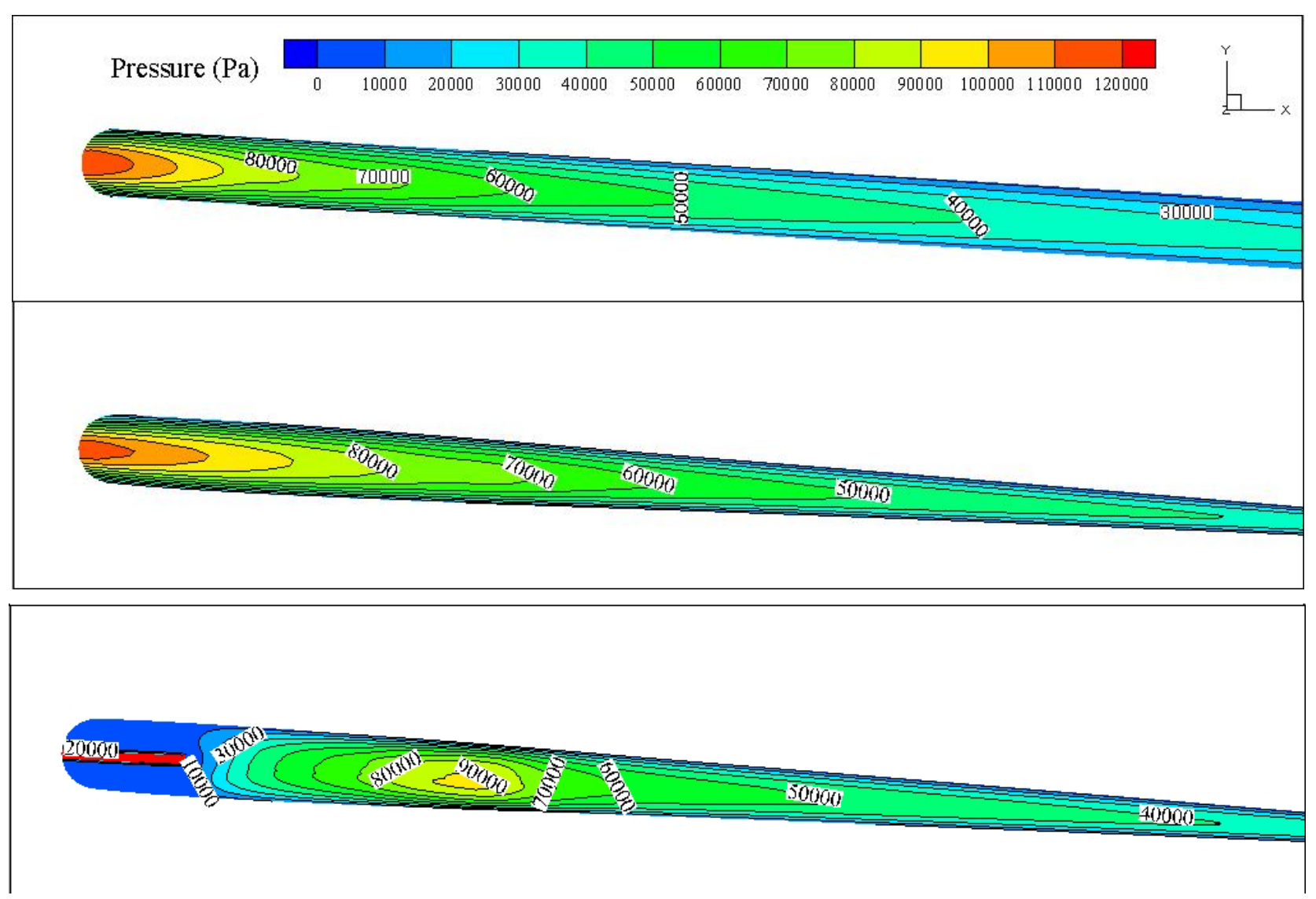

Figure 12 Comparison of pressure distribution for cases 2, 3 and 4 on the blunt surface 


\section{Table caption}

Table.1 Design parameters for cone-derived waverider

Table.2 Configuration parameters for different cases

Table.3 Boundary Conditions for numerical simulation 
Table 1 Design parameters for cone-derived waverider

\begin{tabular}{cc}
\hline Design parameters & Values \\
\hline Ma & 8 \\
\hline$\left(^{\circ}\right)$ & 13.5 \\
$\phi_{l}\left(^{\circ}\right)$ & 50 \\
\hline$l(\mathrm{~m})$ & 1.0 \\
\hline$l_{w}(\mathrm{~m})$ & 0.6 \\
\hline
\end{tabular}


Table 2 Configuration parameters for different cases

\begin{tabular}{|c|c|c|c|c|c|c|}
\hline Schemes & $L_{1} / L_{0}$ & $R / L_{0}$ & $r_{0} / R$ & $r_{1} / r_{0}$ & $S_{\text {jet }} / S_{\text {leading }}$ & $h / R$ \\
\hline Case 1 & \multirow{2}{*}{ / } & 0.00033 & \multirow{2}{*}{ I } & \multirow{2}{*}{ / } & \multirow{3}{*}{ I } & \multirow{3}{*}{ I } \\
\hline Case 2 & & & & & & \\
\hline Case 3 & \multirow{2}{*}{0.06} & 0.00133 & \multirow{2}{*}{0.25} & \multirow{2}{*}{1.0} & & \\
\hline Case 4 & & & & & 0.0086 & 0.25 \\
\hline
\end{tabular}


Table 3 Boundary conditions for numerical simulation

\begin{tabular}{ccc}
\hline Pressure-far-field & Pressure inlet & Wall \\
\hline Perfect gas & air & \\
$\mathrm{Ma}=6.0$ & $\mathrm{Ma}_{\mathrm{in}}=1.0$ & $T_{\mathrm{w}}=300 \mathrm{~K}$ \\
$P_{\mathrm{e}}=2511.01 \mathrm{~Pa}$ & $P_{0 \mathrm{in}}=0.4^{*} P_{0}$ & \\
$T_{\mathrm{e}}=221.65 \mathrm{~K}$ & $T_{\mathrm{ein}}=300 \mathrm{~K}$ & \\
\hline
\end{tabular}

